\title{
Las montoneras como expresión política armada en el camino hacia la constitucionalidad del Perú republicano. Siglo XIX
}

\author{
Serena Fernández Alonso
}

Centro de Estudios Históricos.

Consejo Superior de Investigaciones Científicas. Madrid

Se estudia en este artículo la compleja evolución de la política peruana desde mediados del siglo XIX, con la promulgación de la Carta Constitucional y el gobierno provisional de Mariano Ignacio Prado, hasta la proclamación de Nicolás de Piérola como presidente electo de la República en 1895, momento que marca en la historia interna del Perú el paso del periodo militarista y de profunda agitación política a la estabilidad del sistema constitucional, asumiendo su carácter como entidad nacional de acuerdo a un diseño netamente contemporáneo. Los aspectos centrales del trabajo son el análisis del proceso electoral republicano y sus alteraciones, la formación de los principales grupos políticos del momento y la diversa concreción de la subversión pierolista hasta su triunfo en vísperas del siglo $X X$.

\section{Introducción}

A mediados del siglo XIX, la República del Perú se hallaba aún lejos de alcanzar la estabilidad en el orden político, profundamente marcado por el militarismo y la emergencia de movimientos de agitación contra los gobiernos establecidos.

Para 1867, fecha de la promulgación de la Carta Constitucional, el mandato provisional de Mariano Ignacio Prado no había conseguido asentar la vida política nacional de una manera unívoca y efectiva. El sur y el norte peruano lanzaron acciones revolucionarias que llevarían al poder al coronel José Balta, confirmado constitucionalmente tras las elecciones del año siguiente.

Su gobierno procedió a una decidida política de obras públicas que extendieron el ferrocarril por el país y crearían dificultades 
financieras para el futuro, pero en conjunto, su régimen resultó pacífico y conciliador, lo que permitió evitar durante unos años el estallido de la violencia.

Entretanto, tenía lugar la fundación del Partido Civil por Manuel Pardo, y su ascenso como líder de una nueva etapa política que habría de dar comienzo a partir de su triunfo en las elecciones de 1871-1872. El civilismo aglutinó en sus filas a la clase adinerada peruana y a ciertos sectores de profesionales de clase media e incluso mestizos y mulatos y, durante mucho tiempo, habría de ser "la única fuerza política de dimensión nacional". '

El proceso electoral supuso, no obstante los esfuerzos de Balta, la entrada en un ciclo de violencia exacerbada que ensangrentaría al país durante meses y prepararía la crisis institucional anterior a la guerra con Chile. La polarización entre candidatos, la agitación popular y las manifestaciones de la prensa dividida, marcaron esta transición combativa, estando siempre latente la amenaza de un golpe de Estado. El saldo de la campaña, de varios muertos y numerosos heridos, no oscurecería la victoria de Manuel Pardo, primer presidente civil y uno de los pocos líderes elegidos por voluntad popular. "El universal deseo de paz, tranquilidad y progreso antimilitarista, otorgó al nuevo partido y al candidato civil el respaldo mayoritario de la ciudadanía". ${ }^{2}$

Antes de la segunda vuelta de las elecciones, la injerencia de Balta en el proceso a través de su ministro de Guerra, coronel Tomás Gutiérrez, partidario de un golpe de Estado, habría de dar sus terribles frutos: el aún presidente Balta fue destituido y asesinado, proclamándose Gutiérrez jefe supremo, y desencadenando una persecución desatada contra los civilistas. La oposición a los golpistas del Congreso y las masas populares, llevaría a organizar la resistencia hasta su represión total. Una violencia brutal terminó con los hermanos Gutiérrez, asesinados públicamente, víctimas del odio y el ensañamiento de la población de Lima. pág. 20.

1 Palacios Rodríguez, R.: El Perú Republicano y Moderno. 1868-1968. Lima, 1989,

2 Ibídem, pág. 25. 
Manuel Pardo accedía al sillón presidencial de la República con el respaldo del pueblo y la amargura de estos terribles sucesos. En medio de la intranquilidad social, Pardo diseñó los principios de su política: educación popular, descentralización, racionalidad fiscal y organización electoral.

La inquietud política, aplacada parcialmente durante los cuatro años de régimen civilista, se manifestó en los movimientos revolucionarios de Ayacucho y Cajamarca, así como en el primer intento de Nicolás de Piérola, ex-ministro de Balta, por acceder al poder.

Piérola, nacido en Arequipa en 1839, simbolizaba el sector intransigente y radical. El origen de su oposición a Pardo se explica como reacción al rechazo que se hizo a su elección como diputado por Arequipa en las juntas preparatorias del Congreso de 1872, dominadas por el civilismo. La elección legítima de Piérola por los arequipeños, fue ignorada por los civilistas, que al declararle fuera de la legalidad, propiciaron que el que hubiera sido la encarnación de la oposición constitucional contra el gobierno, lo fuese de la violencia. ${ }^{3}$

A partir de esa fecha y en adelante, Piérola, el Caudillo, el jefe del Partido Demócrata, intuitivo, apasionado y popular, lideraría la resistencia armada contra el militarismo y la descomposición política interna, manifestada dolorosamente durante el gobierno del coronel Mariano Ignacio Prado con el asesinato del ex-presidente Manuel Pardo, ${ }^{4}$ víctima de la reacción anticivilista a que dieron lugar las elecciones de 1876 para su sucesión.

\section{La subversión pierolista hasta la guerra civil de 1895}

La eliminación de Pardo del espectro político de élite, debilitó durante varios años la posición del partido civilista, que se eclipsó temporalmente de la lucha activa por el poder, quedando éste en manos de los pradistas y de los representantes nacionales.

3 Chirinos Soto, E.: Historia de la República. Lima, 1821, pág. 360.

4 Archivo del Ministerio de Relaciones Exteriores del Perú (AMREP), Comunicación oficial al Cuerpo Diplomático del asesinato del presidente Pardo, Legación del Perú en Chile, Legajo 5-4. Lima, 26 de agosto de 1874. 
Con anterioridad a este suceso, Nicolás de Piérola había encabezado dos intentonas de conquistar para sí el gobierno de la nación. La primera de ellas tuvo lugar en la década del 70 . Exiliado hasta entonces en Europa, Piérola entrará en los altos círculos sociales, donde trabará amistad con importantes personajes que acabarán respaldando económicamente su empresa.

En Gran Bretaña fleta un barco para su expedición revolucionaria, conocida ya en 1874 por el gobierno peruano. El "Talismán", con bandera inglesa, tocó puerto en Caldera, donde, tras aprovisionarse, anunció que zarparía hacia Vancouver haciendo escala en El Callao. El gobierno previno a los prefectos provinciales temiendo un levantamiento de los descontentos del interior y ordenándoles una vigilancia exhaustiva de la costa con los buques de la Escuadra. ${ }^{5}$

Simultáneamente, estalló un movimiento en Arequipa dirigido por el hijo del general Vargas Machuca, pero fue sofocado tras hora y media de combate.

El "Talismán" pudo eludir la vigilancia y pasar de Pacasmayo en dirección norte hacia Guayaquil o Panamá. La acción de Piérola, si bien no pudo cumplir sus objetivos revolucionarios, desencadenó serios problemas al gobierno civilista, principalmente de orden diplomático con las autoridades chilenas, a las que acusó de complicidad en las expediciones pierolistas. ${ }^{6}$ Aunque no llegó a producirse una ruptura, se inició una era de fricciones que parecía anunciar el grave conflicto de 1879.

Los pierolistas se agitaban también en el interior del país. Tras su fracaso en tomar la línea férrea de comunicación Mollendo-Puno y la represión del motín de Cajamarca, sus fuerzas se acantonaron en la provincia de Moquegua. El propio presidente partió de Lima al mando de una tropa para oponérsele; las notas oficiales insistían en la tranquilidad reinante:

“...la República se conserva en paz... en ningún Departamento ha sido secundado el movimiento revolucionario, pues dos o tres partidas de

5 AMREP, Legación del Perú en Chile, Varios, 5-4. Lima, 27 de octubre de 1874.

6 AMREP, Notas del Ministerio de Relaciones Exteriores, Leg. 6-4-A. N 121. Santiago, 17 de octubre de 1874 . 
montoneros que se han levantado en el Norte y por los alrededores de esta capital han sido inmediatamente anonadadas por la acción simultánea de los pueblos y de la fuerza pública".

Como se desprende de este testimonio de don José de la RivaAgüero, Piérola contaba con fuerzas terrestres en distintos puntos del territorio nacional, pero de ellas trataremos más adelante.

El "Talismán" navegaba hacia Ilo. Las campañas de los coroneles gubernamentales Rivarola, Velarde y Montero, consiguieron dispersar a los montoneros de Torata, que hubieron de internarse en Bolivia. A pesar de que las partidas montoneras de Albarracín seguían actuando en la provincia de Tarapacá, el gobierno, pretendiendo acallar, incluso en el extranjero, las voces sobre la inestabilidad interna del Perú, reiteraba que "La paz se mantenía inalterable en todo el resto de la República". ${ }^{8}$

La gravedad de los acontecimientos no pudo, sin embargo, ser ocultada, particularmente tras el envío de un vapor de guerra por los británicos, el "Fantome", cuyo gobierno pretendió así castigar la osadía de Piérola de izar en el "Talismán" el pabellón inglés, implicándoles indirectamente en su iniciativa contra el gobierno, de lo que protestaron diplomáticamente.

El incidente no pasó de ahí, pues la campaña de Piérola termina fracasando. Sin embargo, con ella nace la leyenda del Caudillo. El arequipeño se erige a partir de entonces, ya proclamado jefe supremo, en el conspirador que, en cualquier momento y de forma insospechada, puede aparecer en algún punto del Perú poniendo en jaque al gobierno.

Y en efecto, en octubre de 1876, Piérola, siendo ya presidente Mariano Ignacio Prado, desembarca otra vez en Arica. A los pocos días, Torata es escenario de un nuevo levantamiento liderado por el Caudillo, que fracasará en Yacango bajo las armas del general La Cotera, ministro de Gobierno, campaña de la que "El Comercio", diario capitalino, dará detallada noticia. ${ }^{9}$

7 Ibídem. N 131. Lima, 25 de noviembre de 1874.

8 Ibídem.

9 Diario "El Comercio". Año XXXVIII. Lima, 27 de octubre de 1876. 
A mediados de 1877, varios oficiales de la Marina, exhortados por Piérola, se sublevaron en el monitor "Huáscar", anclado en El Callao, proclamándole como jefe supremo y haciéndose a la mar. En el puerto de Cobija, los sublevados le reciben con júbilo, mientras el presidente Prado decreta la condición del "Huáscar" como buque pirata y ofrece una recompensa a quienes lo sometan. De nuevo los ingleses intervienen, enviando a El Callao la fragata "Shah", al mando del almirante Horsey. ${ }^{10}$

Esta iniciativa ha sido valorada por el historiador Chirinos Soto como un error, al considerar:

"el gobierno del Perú da la impresión de aceptar y hasta de buscar la intervención extranjera para reducir por la fuerza a un navío peruano... se diría que el gobierno descansa en los ingleses para aplastar la revolución pierolista"."

Así fue, en efecto. La acción británica en aquel momento marcaría un peligroso precedente, pero, sobre todo, el hecho supuso una victoria política, además de armada, para Piérola, quien se alzó como abanderado de la libertad de la nación peruana frente al extranjero a cualquier precio, incluso de la vida.

Lo que comenzó como una revolución a la que sus compatriotas no respondieron como él había previsto, devino en una defensa a ultranza frente a la intervención británica auspiciada desde el poder. Su determinación, su defensa del honor nacional frente a la debilidad del gobierno, le otorgarían más prestigio del que nunca hubiera soñado como conspirador frente a la autoridad establecida.

Antes del combate, Piérola arenga a su tripulación con estas palabras:

"Caballeros: cada uno a su puesto. Ya la revolución Piérola ha terminado. Ahora no somos sino peruanos a quienes nos ha tocado en suerte defender nuestro pabellón y el de América entera". ${ }^{12}$

10 AMREP, Legación del Perú en Chile, Circular, Leg. 6-4. Lima, 12 de mayo de 1877.

11 Chirinos, E.: Historia..., pág. 363.

12 Ibidem, pág. 366. 
Tras un activo intercambio de fuego entre el "Huáscar" y los navíos británicos, el monitor no arría el pabellón y Horsey suspende la lucha y se retira. El "Huáscar" pone rumbo a Iquique, donde se encuentra fondeada la flota peruana. Piérola sugiere al comandante More unir sus fuerzas y perseguir al enemigo, pero ante su negativa, el Caudillo rinde la nave bajo garantía para toda su tripulación, exceptuando su persona. Este gesto valió a Piérola la libertad, pues More, conmovido, ofrece al revolucionario regresar a El Callao o partir al extranjero.

Las noticias de las acciones del "Huáscar" son recibidas con fervor patriótico por las masas populares de las principales urbes del país, que se manifiestan por las calles dando vivas a Piérola y protestando contra la actitud mostrada por el gobierno. La difícil posición de los pradistas se puso de manifiesto en junio de 1877 , cuando los civilistas Lizardo Montero y Aurelio García y García se sublevaron en El Callao, proponiendo la dimisión del presidente y su reemplazo por La Puerta. Aunque la acción no tuvo éxito, fue evidente que Prado se sostenía en el poder por la fuerza de las armas, mas no por voluntad popular.

El anuncio de la celebración de elecciones en 1880, abrió el cauce a una agitación contenida desde años antes. Sin embargo, la transición a un nuevo régimen se vería alterada por los graves acontecimientos que, en abril de 1879, llevarían al estallido de la guerra con Chile.

Este conflicto sumiría al Perú en un caos en todos los órdenes, del que le sería difícil emerger. "Entre diciembre de 1879, en que el presidente Prado salió del país dejando al mando al general La Puerta y octubre de 1883 , en que se suscribió el controvertido Tratado de Ancón, el ejercicio político estuvo teñido por el signo de la desgracia, ... con una sucesión de regímenes efímeros e inconclusos sin mayores expectativas nacionales: en total, cinco gobernantes en el breve lapso de tres años y diez meses". ${ }^{13}$

No habría de ser Piérola uno de los ausentes en la contienda. Por el contrario, apenas conocida la noticia del conflicto, regresa de

13 Palacios, R.: El Perú..., pág. 38. 
Europa y, abandonando la lucha de su partido, ofrece sus servicios al país, manifestando:

"Por sobre todas las diferencias interiores, ayer como hoy y como mañana, estarán siempre para nosotros la dignidad y la política exterior del Perú”. ${ }^{14}$

Pero la consigna de unidad ante el invasor no fue compartida por los pradistas, quienes rechazaron incluso su propuesta de organizar un batallón de voluntarios. Sin embargo, el destino y el favor popular terminarían volviéndose contra el presidente; a su partida para Europa a finales de aquel año para encargarse de la compra de armamentos, Nicolás de Piérola acepta la dictadura que el pueblo le ofrece, liderando desde aquel momento la encendida resistencia del Perú frente a la agresión chilena en unas circunstancias de inferioridad que permitían predecir la derrota.

Destruido el poder naval peruano, el capitán de navío García y García fue uno de los plenipotenciarios que en nombre del Perú participó en las fallidas conferencias de paz con Chile celebradas en septiembre de 1880 a bordo de la corbeta norteamericana "Lackawana". Cuando Piérola asume el poder, será nombrado secretario general de la Dictadura, en campaña, participando en las batallas de San Juan y Miraflores, defendiendo la ciudad.

Perdida Lima, García y García se retiró con Piérola al interior del país, asumiendo la responsabilidad de todos los ministerios, a la vez que era designado como sucesor del "Califa" en el mando supremo del Perú. Ambos viajan entre marzo y junio de 1881 a La $\mathrm{Paz}$, consiguiendo convencer al presidente boliviano, general Narciso Campero, de reanudar la guerra junto al Perú, al tiempo que agentes a sus órdenes compran armas y pertrechos en Buenos Aires, transportándolos al Perú a través de Bolivia.

Este plan fracasó, al estallar en octubre la revolución de Arequipa, que rompió la unidad. ${ }^{15}$ Los chilenos ocupaban la capital des-

14 Chirinos, E.: Historia..., pág. 369.

15 López Martínez, H.: Guerra con Chile. Episodios y Personajes. 1879-1885. Lima, 1989, págs. 44-45. 
de el mes de enero. Lima, sin gobierno tras el repliegue de Piérola al interior, tiene como únicos representantes a su alcalde y al secretario de Relaciones Exteriores, Pedro José Calderón.

La autoridad se encuentra desgajada, con Piérola en el centro, Lizardo Montero en el norte y Solar en el sur, ninguno de los cuales puede dominar Lima. A pesar de ello, "Piérola expresa su voluntad de continuar como jefe supremo, pasando por alto las tentativas chilenas para la formación de un gobierno distinto e insiste en la continuación de las negociaciones de paz", ${ }^{16}$ reiterando la no aceptación de cesión territorial.

Sin embargo, su ausencia de Lima y la presión del ejército chileno, acabarán obligando a las Juntas de Notables capitalinas a elegir un gobierno. De aquellas tensiones emergerá el gobierno de Francisco García Calderón, en uno de los momentos más trágicos de la historia peruana. Su mandato resultó efímero y complejo, rodeado de múltiples inconvenientes que terminan con su prisión en Chile desde noviembre de 1881 , ante su negativa a suscribir un tratado de paz que implique pérdidas territoriales a la nación. Inmediatamente, la elección de Lizardo Montero se hace para mantener la continuidad del régimen y evitar la anarquía entre los grupos políticos. Cáceres e Iglesias mantienen la resistencia en el centro y en el norte.

Piérola renuncia al poder y mantiene una posición de neutralidad mientras, pretendiendo reconstruir la unidad nacional, funda el Partido Demócrata. Oponiéndose así a las condiciones de paz que pretende imponer Chile, ${ }^{17}$ Piérola viajará a Europa intentando hacer uso de sus contactos para que tanto Francia como Gran Bretaña presionen sobre Washington para evitar la desmembración del territorio nacional. Su iniciativa no llegaría a concretarse. A su regreso a Lima, Iglesias había capitulado frente a los chilenos y firmado el humillante Tratado de Ancón el 20 de octubre de 1883.

16 Guerra Martiniere, M.: La ocupación de Lima. (1881-1883). El Gobierno de García Calderón. Lima, 1991, pág. 153.

17 AMREP, Servicio Diplomático del Perú, Guerra con Chile, Legación en España, Leg. 5-13. Resumen de noticias periodísticas sobre el conflicto. Madrid, 13 de marzo de 1881. 
Cáceres lo reconoció como un hecho consumado, pero organizó la resistencia frente al gobierno de Iglesias, hasta lograr su triunfo el 30 de noviembre de 1885 .

Las elecciones del año siguiente, en medio de la desolación por la derrota, dieron la victoria al esforzado jefe militar de la reciente guerra, es decir, confirmaron a Andrés Avelino Cáceres en el poder. Sus esfuerzos por lograr la reconstrucción nacional se vieron trabados por diversas agitaciones parlamentarias que obligaron a repetidos cambios de gabinete. Su convocatoria a elecciones en 1890 llevó al poder al coronel Remigio Morales Bermúdez. El vaivén político consagraba de nuevo como fórmula la alternancia de caudillos militares. Piérola, entretanto, había sido hecho prisionero y sometido a proceso judicial por los actos de la Dictadura, así que no estuvo presente en las elecciones.

Los pocos meses del gobierno de Bermúdez fueron testigos de una sangrienta revolución en el cuartel de Santa Catalina y de la fuga de Piérola, que pudo salir hacia Guayaquil apoyado por sus partidarios y tomar la vía de Panamá hacia Europa, de donde no regresaría hasta 1893, para organizar de nuevo la sublevación desde Chile en defensa de las libertades políticas. ${ }^{18}$

La ocasión no estaba lejos. Bermúdez fallecería prematuramente y las elecciones llevarían a la presidencia de nuevo a Cáceres. esta vez sin el respaldo mayoritario de la población. En un momento de graves dificultades para la nación, el general Cáceres encontró, además, la oposición de los partidos Unión Cívica y Demócrata, "coaligados desde fines de 1894 en defensa de la libertad electoral y de la autenticidad del sufragio" 19 bajo el liderato de Nicolás de Piérola, nombrado delegado nacional.

El frente de la coalición contra el gobierno adquiriría dimensión nacional a través de un mecanismo de claro carácter espontáneo y base popular, que generalizaría y abriría, por fin, el camino de Piérola hacia el poder: las montoneras.

18 Ulloa, J.A.: Don Nicolás de Piérola. Una época de la Historia del Perú. Lima, 1924, págs. 250-270.

19 Palacios, R.: El Perú..., pág. 46. 


\section{Origen, caracteres y acción de las montoneras en el Perú a finales del siglo XIX}

Las montoneras, como fuerzas irregulares de escasa preparación militar y recursos pero enorme efectividad estratégica, tienen su origen en las guerrillas españolas de la Guerra de la Independencia frente a los franceses, y fueron utilizadas en Sudamérica ya desde las guerras de Emancipación.

Bien estudiadas por Salazar Vera y Vergara Arias ${ }^{20}$ para el período independentista, y eludiendo por nuestra parte entrar en las disquisiciones sobre el concepto de montoneras frente a los de partidas y partida de guerrillas, pasaremos a analizar el caráeter de estos grupos armados en el asalto al poder de Nicolás de Piérola en los últimos años del siglo XIX.

Las montoneras constituyeron organizaciones populares de surgimiento espontáneo en defensa de una causa común frente a un adversario político al que pretenden derrocar del poder por medio de las armas. Integradas por gentes de una misma localidad y de la más variada extracción social, suelen ser dirigidas por un representante en quien el grupo confía y a quien obedecen en las acciones bélicas. No será extraño encontrar en ellas hombres, mujeres, niños y hasta ancianos, comprometidos con la empresa y dispuestos a colaborar, si no empuñando armas, sí consiguiendo víveres, actuando como espías del enemigo, proporcionando información de utilidad para la campaña o encubriendo y ocultando a sus protagonistas.

Se trata, pues, de grupos de insurrectos frente al poder establecido que, armados precariamente y provistos de caballos, mulas y pertrechos que capturan al enemigo, cuentan a su favor con un extraordinario conocimiento del medio geográfico, en el que actúan con gran audacia y rapidez.

20 Salazar Vera, Guerrillas o montoneras de los Altiplanos de Junín y Bombón. Lima, 1984; Vergara Arias, G.: Montoneras y guerrillas en la etapa de la Emancipación del Perú (1820-1825). Lima, 1973. Id., En torno a la denominación de montoneras y partidas de guerrilla. "Nueva Crónica", núm. 1. Lima, 1963, págs. 191-198. 
Su modalidad de lucha es el ataque sorpresivo y la retirada inmediata, lo que les permitía infligir serios daños al enemigo sin entrar en un enfrentamiento directo para el que no se hallaban técnicamente preparados y del que, por la inferioridad de medios, no podían salir victoriosos.

Su objetivo consistía en entorpecer el avance de las tropas del bando al que se oponen, más que en trabar batalla y obtener un triunfo definitivo sobre sus más organizadas fuerzas. Así, recorrían los valles, cerros y quebradas andinos provocando estragos sobre los frentes de ejército mediante tácticas de emboscada y golpes de mano que les permiten perfeccionar sus métodos y requisar ganado, provisiones y armamento para posteriores ataques.

No se trata, por tanto, de un ejército popular de acción integrada, puesto que cada montonera tiene su área de acción y surgen y actúan de forma dispersa e independientemente unas de otras, aunque, indudablemente, responden a un plan global establecido por los líderes del movimiento, con los que están en comunicación.

No hay intercambio de recursos entre las partidas, sino que cada una de ellas busca los medios con que sostenerse y sobrevive en función de las condiciones más adversas con que se encuentra.

Sí hay, según Vergara Arias, un vínculo de unión entre los miembros de cada montonera y unas reglas paramilitares que garantizan la unidad y castigan la deserción y los abusos. En nuestra opinión, basada en la documentación inédita que analizaremos más adelante, la hermandad entre los miembros de una partida tenía carácter espontáneo y voluntario, emanado estrictamente del compromiso con la causa que la ha llevado a emerger y carente de respaldo en reglas o principios más allá de la lealtad de cada individuo, razón que explica que las montoneras se agrupen con la misma rapidez con que se disgregan, en no pocos casos.

En cuanto al sostenimiento de las mismas, existen numerosos testimonios del apoyo de los hacendados con dinero y productos de sus tierras, aunque no es menos cierto que el recurso a las exacciones y cupos forzosos fue un mecanismo muy frecuente para paliar las dificultades de una movilización que obligaba a abandonar las actividades agrícolas, mineras y comerciales de una zona. En suma, 
predominaron la escasez de alimentos y la precariedad de vestidos y armamento, por lo que no fue excepcional que los montoneros causasen daños y fuesen protagonistas de excesos en las localidades por las que pasaban, protestados por las autoridades y pobladores. En ciertos casos, no dudaron en apropiarse de los fondos de las $\mathrm{Ca}$ jas municipales y de la institución eclesial.

En los años 90 del siglo XIX, el territorio republicano se hallaba salpicado de grupos guerrilleros que actuaban en apoyo de Piérola hostigando a las fuerzas gubernamentales de Cáceres. Paradójicamente, como ha señalado Basadre, "Cáceres se vio hostilizado por sus enemigos internos con el sistema de las montoneras que él había utilizado genialmente para combatir al enemigo exterior". ${ }^{21}$

La revolución pierolista se había generalizado. En diversos puntos del territorio nacional, se armaron partidas de paisanos para derrocar al militarismo. Pronto se llegó a la guerra abierta. Primero fueron las conspiraciones secretas, en muchas de las cuales tuvieron que ver súbditos españoles. Así, ya en 1888, las autoridades locales informaban al prefecto del Departamento de Lima de las dificultades para apresar a los sediciosos:

“... no he dejado de vigilar un solo instante por la tranquilidad del ciudadano y conservación del orden público; he perseguido incesantemente tanto al bandolero como a los conspiradores, habiendo puesto a disposición del Sr. Juez del Crimen a los primeros... por desgracia, con los segundos no me ha sido posible hacer lo mismo.

En conspiraciones contra gobiernos constituidos es muy difícil tomar las pruebas, a pesar del conocimiento cierto que tengan las autoridades... A los conspiradores que rodeados de toda clase de precauciones y apoyados muchas veces por personas que aunque son ajenas a la política, les prestan protección por el solo hecho de evitarles los peligros consiguientes a su delito en caso de ser descubiertos, se hace aún más difícil conseguir su captura, porque se necesitan las pruebas que tanto saben ocultar". 22

21 Basadre, J.: “Antecedentes de la Guerra con Chile", Historia del Penú Republicano. Vol. VII. Lima, 1980.

22 Biblioteca Nacional del Perú (BNP). Sección Manuscritos, Mss. D 6457. Relación de los SS. Jefes y oficiales y demás personas que se encuentran en esta plaza como conspiradores. Lima, 26 de septiembre de 1888. 
La subversión era, sin embargo, de mayor intensidad en las localidades del interior. La fragosidad del terreno y la precariedad de medios defensivos de las autoridades provinciales, favorecían las acciones guerrilleras. Así se expresaba el subprefecto de Huaylas en el parte oficial remitido a Lima sobre los sucesos ocurridos en Caraz:

"Son las doce de la noche, hora en que se me participa extraoficialmente que, a prima noche ha tenido lugar en Caraz un bochinche a balazos entre los demócratas y constitucionales (...) y que quedaba la población en gran alarma y haciéndose disparos de rifle y revólver por todas direcciones.

Como en Caraz no hay más que tres guardias, por haber desertado uno, espero aquí la fuerza que en dos ocasiones he pedido... la impotencia en que se encuentra la Subprefectura para contener estos desórdenes, y en particular ahora que los ánimos están sobreexcitados y ambos partidos armados...". 23

También en la zona norte, Departamentos de Lambayeque, La Libertad y Piura, las acciones de los montoneros se dejaron sentir. Bajo las órdenes del hacendado Oswaldo Seminario y sus parientes Teodoro, Edmundo y Augusto, la montonera recorrió el trayecto Paita-Iquique para conseguir armas en varias ocasiones, cortó tramos telegráficos o los utilizó para sus fines, frente al estupor del prefecto de Piura Fernando Seminario, pariente de los insurrectos, que no pudo someterlos y se agotó pidiendo refuerzos al director del Gobierno. ${ }^{24}$

El centro peruano - Departamentos de Huánuco, Ancash y Pasco- estuvo bajo la influencia de Augusto Durand, un abogado y rico hacendado que, erigido en jefe político y militar, puso en jaque a las autoridades de aquel área.

En el sur, en la zona comprendida por Cañete, Chincha, Lurín, Pisco y parte de Ica, los jefes montoneros fueron Felipe Santiago Oré y Vicente del Solar, mientras Arequipa quedaba en manos

23 BNP, Secc. Manuscritos, Copia de Oficios de la Subprefectura. Yungay, 26 de marzo de 1894.

24 BNP, Secc. Manuscritos, Mss. D 7265. Documentos relativos a los sucesos promovidos por facciosos en Piura. Piura, 29 de junio de 1894. 
del cubano Pacheco Céspedes y los coroneles Yessup, Ramos Pacheco y La Rosa, y Puno y Cuzco en las de Mariano Nicolás Valcárcel.

Existen pruebas documentales del intento de los revolucionarios por captar el apoyo de las autoridades para la causa pierolista, ofreciéndoles a cambio ascensos y puestos en la futura administración. Aunque en ciertos casos lo obtuvieron, son frecuentes los testimonios sobre la fidelidad de los prefectos al gobierno del entonces presidente Borgaño. ${ }^{25}$ En octubre de 1894, el subprefecto de Chiquián informaba de la situación a su superior en Huaraz:

"Siendo escandalosas las exacciones que los montoneros D. Rojas Loayza y Manuel Trucios cometen en la capital de esta provincia, en donde tienen presos al Sr. Juez de Primera instancia, Dr. D. Romualdo Barreto, y Sres. D. José González y José V. García, a los que ocupan pagar fuertes cupos ... todo esto pondrá al corriente de esa superioridad de que los montoneros están casi en posesión de la provincia completa....". ${ }^{26}$

En numerosos ataques de las montoneras pierolistas, fue fundamental la captura de municiones y caballos a las guarniciones asaltadas y la toma de líneas y material rodante del ferrocarril. Junto al telégrafo, ello permitiría a los revolucionarios interrumpir las comunicaciones entre las tropas oficiales y el gobierno, a la vez que agilizar los desplazamientos y embestidas de sus partidas.

Referiremos a continuación el móvil empleado en el ataque de la montonera de Arana en la región de Palpa:

“Anoche a las 8.30 p.m. fuimos atacados en el cuartel de esta plaza por una montonera de 20 hombres que divididos en dos secciones, nos hacían fuego de frente y por el flanco izquierdo tomando posición del atrio de la iglesia y de los portales, penetrando por los corrales de las casas disfrazados de mujeres, haciéndonos fuego nutrido que sostuvimos por espacio de hora y media hasta lograr desalojarlos...". ${ }^{27}$

25 BNP, Secc. Manuscritos, Mss. D 6445 y D 5289. Ica y Cuzco, julio 1894.

26 Ibídem, Mss. D 4803. Huaraz, 29 de octubre de 1894.

27 Ibídem, Mss. D 7333. Palpa, 11 de marzo de 1895. 
En octubre de 1894, Piérola decide, finalmente, su regreso al Perú. A bordo de una chalupa pequeña y en condiciones críticas, burlando las patrullas de las naves gubernamentales, el líder demócrata realizó una penosa travesía de 300 millas desde Iquique a Puerto Caballas, cerca de Pisco. Una vez desembarcados, partieron hacia Chincha por difíciles caminos, ingresando en la ciudad el 3 de noviembre y siendo aclamados por la población. Allí asumió Piérola el título de delegado nacional, desplazándose después hacia Cañete y Huarochirí, y estableciendo su base de operaciones en Cieneguilla.

A poco de conocerse la noticia de su vuelta al Perú, las autoridades capitalinas, previendo un inminente ataque a la sede del gobierno, comenzaron los preparativos de defensa de la ciudad. La inquietud hizo presa de la población al conocerse el avance de las montoneras, que divididas en tres frentes, se lanzaron sobre la capital el 16 de marzo de 1895.

Lima fue escenario de cruentos combates entre las fuerzas caceristas y el ejército invasor, que contó con el apoyo decidido del pueblo. La lucha llegó a adquirir matices trágicos, llenándose las calles de cadáveres, heridos y moribundos, que obligaron a decretar un armisticio para enterrar a los muertos y evitar el peligro de epidemia.

Agotadas ya las posibilidades de la contienda, las intensas gestiones del Cuerpo Diplomático permitirían llegar a la firma de un acuerdo de paz por el que el general Cáceres dimitía del mando en una Junta Provisional de Gobierno cuyos miembros, nombrados por él mismo y por Piérola, procederían a convocar elecciones generales y a establecer las medidas necesarias para garantizar la seguridad de la población y la salida de las tropas de la ciudad.

Presidida la Junta por don Manuel Candamo, los cuatro representantes se hicieron cargo de los ministerios. La propuesta del delegado chileno en Lima para constituir un protectorado extranjero con la participación de los cuerpos diplomáticos residentes en la capital, no prosperó. ${ }^{28} \mathrm{La}$ labor de la comisión fue fundamental en esta etapa de transición y reconstrucción nacional. Sus medidas más

28 Palacios, R.: El Perú..., pág. 63. 
destacables fueron la liberación de los presos políticos, prueba tangible de una voluntad de conciliación, la fijación de los principios de la Constitución de 1860 como bases de la actuación del Poder Ejecutivo y la contratación de empréstitos con bancos ingleses e italianos para paliar las urgencias del Erario.

Se entraba así, finalmente, en un período de paz interna conquistado a un alto precio para la población peruana, sin cuyo respaldo es dudoso que el caudillo hubiese logrado hacer triunfar su revolución. Su llegada al poder era, sin paliativos, el triunfo de la voluntad del pueblo sobre la autoridad pretendidamente omnímoda de los generales.

\section{Consideraciones finales}

La acción de las montoneras dio paso, inmediatamente, al desarrollo de la expresión electoral legítima. El 8 de septiembre de 1895, Nicolás de Piérola fue proclamado presidente electo de la $\mathrm{Re}-$ pública del Perú. La legación española se apresuró a expresar su adhesión y el deseo de entablar las mejores relaciones con el nuevo mandatario. ${ }^{29}$

Su llegada al poder marcó el inicio de una etapa en la vida política nacional. Decidido partidario de la constitucionalidad frente al militarismo, el Califa, el incansable montonero, pudo ver cumplidos sus deseos de avenencia entre las distintas posiciones ideológicas que habían agitado la vida política en las pasadas décadas. A él se debió el llamamiento de todas ellas para trabajar por el bien común de la nación olvidando las estrechas miras del partidismo.

Los resultados de aquel esfuerzo, por primera vez unívoco, no tardaron en manifestarse en todos los ámbitos de la vida nacional. El régimen de Piérola fue el artífice de la reconstrucción de la República, que anunciaba ya -con el desarrollo de la minería, el comercio y la agricultura, la reorganización de la hacienda y la ad-

29 AMREP, Sección Diplomática, Legación de España en el Perú, núm. 27. Lima, 11 de septiembre de 1895. 
ministración, y el regreso de los capitales extranjeros- los importantes progresos y el esplendor económico del Perú a partir de 1900.

Las exacerbadas contiendas políticas de las décadas precedentes, se aplacaron y encauzaron en un nuevo orden jurídico e institucional que propiciaría el desarrollo de un Estado más sólido y próspero. Hubo poderosas reformas en el sistema electoral, se estableció el patrón oro, surgieron sociedades anónimas e importantes industrias; se estabilizaron las relaciones internacionales, se reorganizó el ejército y se dio un serio empuje a la educación. El país se vio más integrado gracias a la extensión de la red telegráfica y ferrocarrilera, tendiendo a crecer lo que Basadre calificó como "La armonía entre el país legal y el país real, dando paso a la formación de un Estado más jurídico y administrativo y menos parasitario o extorsionista, a cuyo amparo se desarrolló la riqueza nacional e individual". ${ }^{30}$

El Perú, finalmente, salía de un profundo caos interno para asumir los retos del siglo $\mathrm{XX}$ con un espíritu de restaurada confianza en sí mismo, como entidad nacional y como pueblo. En este sentido, puede afirmarse que el pierolismo dio sentido al país moldeándolo de acuerdo a un diseño netamente contemporáneo.

30 Palacios, R.: El Perú..., pág.66. 